\title{
A Comparisonal Study on Unbalance Failure in the Perspective of Vibration and Electrical Consumption Analysis
}

\author{
Salih Seçkin Erol *1 \\ Accepted 3rd September 2016
}

\begin{abstract}
In this research, condition of resonance effect which is a common problem for mechanical constructions has been studied in perspective of unbalance failure of a bearing. A test setup designed respect to case practices; constructed and located in laboratory conditions. A bearing in the electrical motor, that is one of the elements in the test setup, has been selected for gathering data in vibration and electrical consumption during the test. The purpose of the research is testing condition of unbalance failure and resonance for studying comparison in various predictive maintenance approaches. Test has been implemented under the electricity frequency of 40.5 $\mathrm{Hz}$ that induced the electrical motor for determining rotational speed. According to the analysis results, inspecting of unbalance failure and resonance problem has been detected more clearly by vibration analysis.
\end{abstract}

Keywords: electrical consumption, unbalance, resonance, vibration, fourier.

\section{Introduction}

Energy efficiency maintenance techniques are in the stage of rapid development due to competitive markets and globalization. Mainly, enterprises of developing countries are in demand of high technology implementations for mechanical maintenance in order to leave classic techniques such as breakdown maintenance, periodic maintenance etc. Vibration based maintenance is one of the techniques which is used commonly in industries that prefer predictive maintenance. As long as since the stage of failure initiation, machines consume more electricity respect to the stress in machine elements. By studying data belongs to electricity consumption regarding voltage and current, it brings a newer approach on detecting failure types and severity respect to the signal processing. Vibration analysis is based on the signals those gathered as targeting on bearing, but electrical data is received over electricity usage of the motor. Interpretation of vibration analysis has algorithm based on rotation frequencies caused by the rotational speed; and electrical consumption analysis is based on signals of electrical frequency that is in use.

Nowadays, reliability concept is used more commonly in the development of manufacturing industries. Design of products with high reliability is needed, but against to deterioration in the life cycle of the product, maintenance is a method in maintenance [1]. Prognostic and diagnostic terms are known from medical areas and they are used for the machine health as well. Currently, a variety of sensors and some other equipments are used successfully in receiving signals for studying the root causes of the mechanical failures [2]. In order to cope with the competitive markets, assistance of the high technology such as sensor technology is crucial for the enterprises. On the other hand, investment on high technology does mean always positive results. Appropriate sensors for the target aim, qualified personnel and right interpretation of the data are other important factors for successful actions [3]. One of the failure detection methods for

${ }^{1}$ Mechanical Engineering Department, Engineering Faculty, Kilis 7

Aralik University, 79000, Kilis/Turkey

* Corresponding Author: Email: sserol@kilis.edu.tr

This journal is @ Advanced Technology \& Science 2013 electrical motors is collecting signals of voltage and current and study them [4].

Electrically forced machines are very common in production areas. Breakdown of these machines brings many losses to the enterprises such as time loss, quality loss, capita loss. In order to prevent these kind of losses, maintenance need was born [5].

Machines have characteristic properties on failure types respect to the vibration signals oscillated. Machine failures are mostly studied under assistance of vibrational analysis [6]. Spectrum analysis is a method for identifying the frequencies of a signal. Fourier transform deals with signals that are studied respect to the time parameter as sine and cosines; and to the frequency parameter that is the same signal which is categorized according the frequencies [7].

\section{Materials and Methods}

Test setup constructed through consisting of double inlet fan, AC induction motor, five feet of flexible coupling and frequency inverter. The test setup is constructed over a steel sheet and a steel tripod. The test setup is put up on a double-decker rubber sheet that is mounted between the test system and the tripod; also, a vacuum rubber below the feet of the tripod takes place over the floor. This system with a data acquisition card and an induction motor is communicated with monitoring system through a computer. Testing system in Figure 1 presents a real appearance from testing setup. 


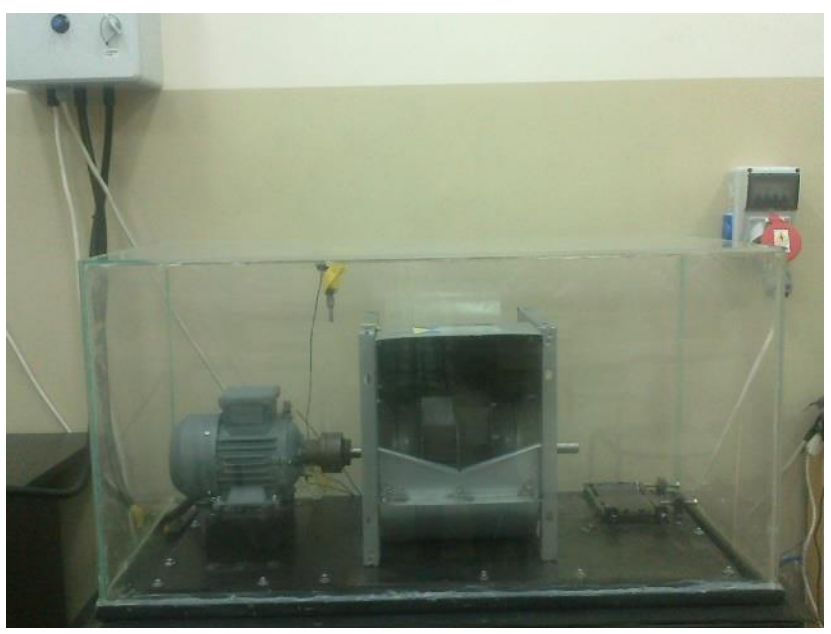

Figure 1. Overall view of the test setup

Frequencies took place in the test $(\mathrm{T})$ and measured $(\mathrm{M})$ are given in Table 1. Theoretical frequencies means the value set on the digital frequency changer; according to data studied during the application, actual frequency ranging had some losses. $1 \mathrm{x}$ is named as a frequency that is known as fundamental frequency; $2 \mathrm{x}, 3 \mathrm{x}$ and the upper orders are harmonics of the fundamental frequency. In Table 1, the frequency is presented with the symbol of $\mathrm{f}$ for frequency converter and harmonic order is shown with symbol of $h$.

Table 1. Frequencies in theory and practice

\begin{tabular}{|c|c|c|c|c|c|c|c|c|c|c|c|}
\hline \multirow{2}{*}{$\begin{array}{c}\text { (f) } \\
\text { (f) }\end{array}$} & \multicolumn{2}{|c|}{$\mathbf{1 x}$} & \multicolumn{2}{|c|}{$\mathbf{2 x}$} & \multicolumn{2}{|c|}{$\mathbf{3 x}$} & \multicolumn{2}{|c|}{$\mathbf{4 x}$} & \multicolumn{2}{|c|}{$\mathbf{5 x}$} \\
\cline { 2 - 11 } & $\mathbf{T}$ & $\mathbf{M}$ & $\mathbf{T}$ & $\mathbf{M}$ & $\mathbf{T}$ & $\mathbf{M}$ & $\mathbf{T}$ & $\mathbf{M}$ & $\mathbf{T}$ & $\mathbf{M}$ \\
\hline $\mathbf{4 0 . 5}$ & 40.5 & 39.06 & 81 & 78.12 & 121.5 & 117.18 & 162 & 156.24 & 202.5 & 241.56 \\
\hline
\end{tabular}

Measurements are received during the tests at electrical frequency of $40.5 \mathrm{~Hz}$ and rotational level was measured as $2350 \mathrm{~min}^{-1}$. Frequencies of faults and harmonics are studied for calculating the bearing and fan-induced vibrations of the testing setup.

Bearing relevant equations with the basic failure frequency calculations and respect to measurements are given in Table 2.

Table 2. Frequencies of faults

\begin{tabular}{|c|c|c|c|c|c|c|}
\hline $\mathrm{f}$ & $\omega_{\mathrm{s}}$ & $\begin{array}{c}\omega_{\mathrm{bpf}} \\
(\mathrm{Hz})\end{array}$ & $\begin{array}{c}\omega_{\mathrm{c}} \\
(\mathrm{Hz})\end{array}$ & $\begin{array}{c}\omega_{\text {bpfo }} \\
(\mathrm{Hz})\end{array}$ & $\begin{array}{c}\omega_{\text {bpfi }} \\
(\mathrm{Hz})\end{array}$ & $\begin{array}{c}\omega_{\text {bsf }} \\
(\mathrm{Hz})\end{array}$ \\
\hline 40.5 & 39.06 & 390.6 & 14.84 & 118.74 & 193.76 & 76.69 \\
\hline
\end{tabular}

$\omega_{\text {bpfo }}:$ Outer ring passing frequency $(\mathrm{Hz}), \omega_{\text {bpfi }}:$ Inner ring passing frequency $(\mathrm{Hz}), \omega_{\mathrm{bsf}}:$ Ball spin frequency $(\mathrm{Hz}), \omega_{\mathrm{c}}$ : Cage frequency $(\mathrm{Hz}), \omega_{\mathrm{s}}$ : Shaft frequency $(\mathrm{Hz}), \omega_{\mathrm{bpf}}:$ Fan blade passing frequency $(\mathrm{Hz})$

Tested bearing has been presented in Figure 2.

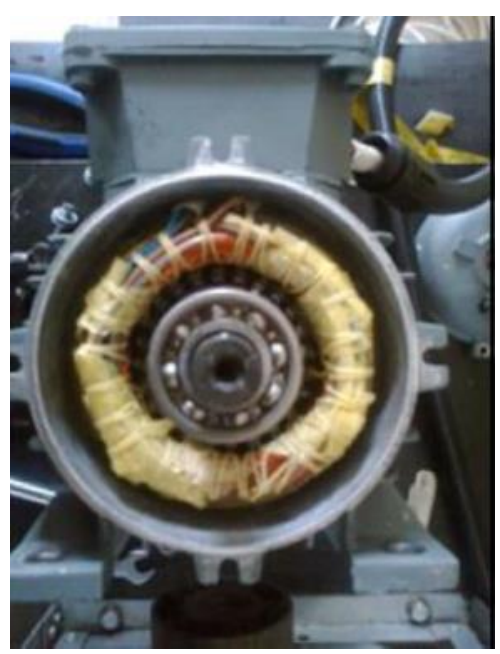

Figure 2. Tested bearing

In order to establish unbalance effect, load of $23 \mathrm{~g}$ is mounted on the wing of the fan same as in Figure 3.

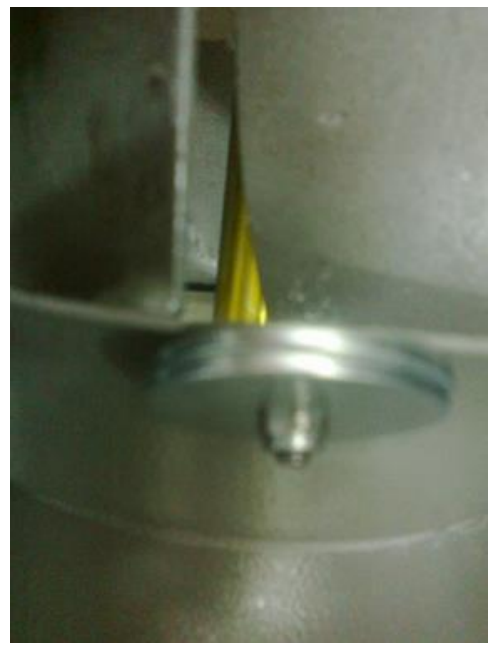

Figure 3. Load on wing

In order to study measurements, non-processed data from vibrational techniques have been processed with FFT (Fast Fourier Transform) method and data has been transferred for making analysis. Electrical consumption data has been processed respect to the algorithm of the device software and analysis are done respect to the PSD (Power Spectrum Density) and trend indicators.

\section{Experimental}

Vibration measurements are received in radial (vertical) and axial direction during the tests. Vibrational data captured with sensors connected to a DAQ (Data Acquisition Card) and processed with its software. In order to identify natural frequencies for comparison, damping tests are practised on test setup when the system is not in rotational movement. Data relevant with electrical consumption has been captured through an electronic device connected to electrical circuit of the motor and analyzed with its software. 


\section{A. Vibration Analysis}

Under the effect of unbalance failure in axial direction, respect to the findings at frequency of $40.5 \mathrm{~Hz}$; harmonic $1 \mathrm{x}$ is detected with the highest amplitude. $1 \mathrm{x}$ is the characteristic feature of unbalance failure. Similarly with the radial direction, signal at harmonic $1 \mathrm{x}$ has the highest amplitude with $0.785 \mathrm{~m} / \mathrm{s}^{2}$ but less than the radial direction which is $1.19 \mathrm{~m} / \mathrm{s}^{2}$. In comparison with highest five amplitude signals in axial and radial direction, four signals are detected at same frequencies as $39.06 \mathrm{~Hz}, 120.8 \mathrm{~Hz}$, $78.13 \mathrm{~Hz}$ and $947.3 \mathrm{~Hz}$. In the axial direction, natural frequency signal at $1027.8 \mathrm{~Hz}$ is excited by the bearing signal at $69 \mathrm{x} \omega \mathrm{c}$ has been detected which does not exist in radial direction dominant signals.

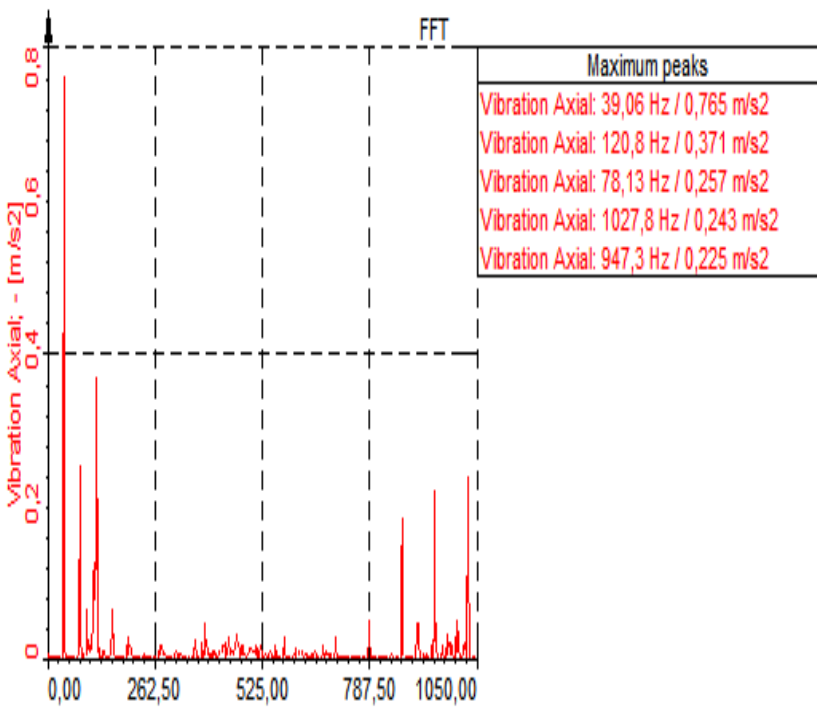

Figure 4. Spectrum in axial way

Respect to the Figure 4 and Table 3, unbalance condition increased the vibration magnitude of signals at the element passing zone.

Table 3. Dominant signals in axial way

\begin{tabular}{|c|c|c|c|c|c|}
\hline MEASUREMENT (A) & $\mathbf{1 . S}$ & $\mathbf{2 . S}$ & $\mathbf{3 . S}$ & $\mathbf{4 . S}$ & $\mathbf{5 . S}$ \\
\hline Unbalance & $1 \mathrm{x}$ & $\begin{array}{c}f_{n} \\
(3 \mathrm{x})\end{array}$ & $\begin{array}{c}f_{n} \\
2 \mathrm{x}\end{array}$ & $\begin{array}{c}f_{n} \\
\left(69 \mathrm{x} \omega_{\mathrm{c}}\right)\end{array}$ & $\left(64 \mathrm{x} \omega_{\mathrm{c}}\right)$ \\
\hline
\end{tabular}

According to the spectrum analysis of radial direction measurement in Figure 5; unbalance harmonic 1x has been detected as the most dominant signal in radial direction with the amplitude of $1.19 \mathrm{~m} / \mathrm{s}^{2}$. In radial direction, signal at $860.72 \mathrm{~Hz}$ that is the upper harmonics of cage frequency $\left(58 \mathrm{x} \omega_{\mathrm{c}}\right)$ excited a signal at the frequency $866.7 \mathrm{~Hz}$ which is a natural frequency and consequently superharmonic resonance has been observed with the highest signal amplitude as $0.278 \mathrm{~m} / \mathrm{s}^{2}$. The other resonance effects are detected at second and third dominant signal in frequencies of $947.3 \mathrm{~Hz}$ and $120.8 \mathrm{~Hz}$. Signal in upper order of cage frequency at $949.76 \mathrm{~Hz}\left(64 \mathrm{x} \omega_{\mathrm{c}}\right)$ has excited the natural frequency at $947.3 \mathrm{~Hz}$ and subharmonic resonance has been detected with the amplitude of $0.4 \mathrm{~m} / \mathrm{s}^{2}$. Signal at $117.18 \mathrm{~Hz}(3 \mathrm{x})$ has excited the natural frequency at $120.8 \mathrm{~Hz}$ and superharmonic resonance has been detected with the amplitude of $0.298 \mathrm{~m} / \mathrm{s}^{2}$. Signal at harmonic $2 \mathrm{x}$ has been appeared as the fourth dominant signal.

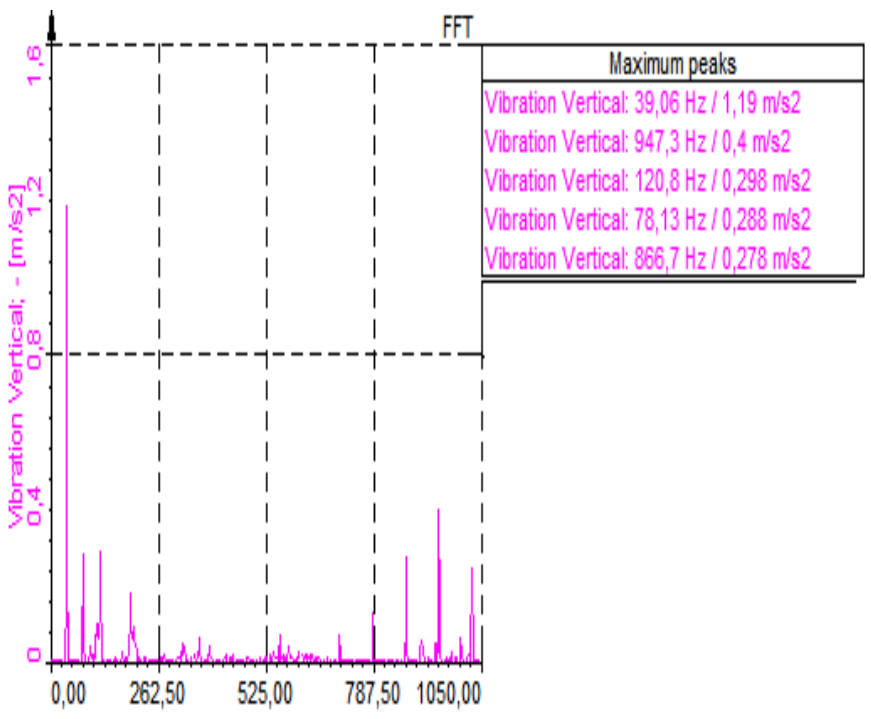

Figure 5. Spectrum in vertical direction

Respect to the Figure 5 and Table 4, unbalance condition increased the vibration magnitude of signals at the element passing zone.

Table 4. Dominant signals in radial way

\begin{tabular}{|c|c|c|c|c|c|}
\hline MEASUREMENT (V) & $\mathbf{1 . S}$ & $\mathbf{2 . S}$ & $\mathbf{3 . S}$ & $\mathbf{4 . S}$ & $\mathbf{5 . S}$ \\
\hline Unbalance & & $\begin{array}{c}f_{n} \\
\left(64 \mathrm{x} \omega_{\mathrm{c}}\right)\end{array}$ & $\begin{array}{c}f_{n} \\
(3 \mathrm{x})\end{array}$ & $2 \mathrm{x}$ & $\begin{array}{c}f_{n} \\
\left(58 \mathrm{x} \omega_{\mathrm{c}}\right)\end{array}$ \\
\hline
\end{tabular}

\section{B. Electrical Consumption Analysis}

Standart deviations in measurements are evaluated in perspective of electrical consumption, data is given in PSD analysis and trend analysis. Respect to PSD analysis in Figure 6, peaks can be seen at the orders of $40.5 \mathrm{~Hz}$. Highest three amplitudes are on $40.5 \mathrm{~Hz}$, $81 \mathrm{~Hz}$ and $121.5 \mathrm{~Hz}$. According to the methodological approach of device software, band at the main frequency represents the condition of the rotor, band at the second order represents the unbalance failure and band at the third order represents the any other failure. The PSD analysis takes attention to rotor and unbalance failure.

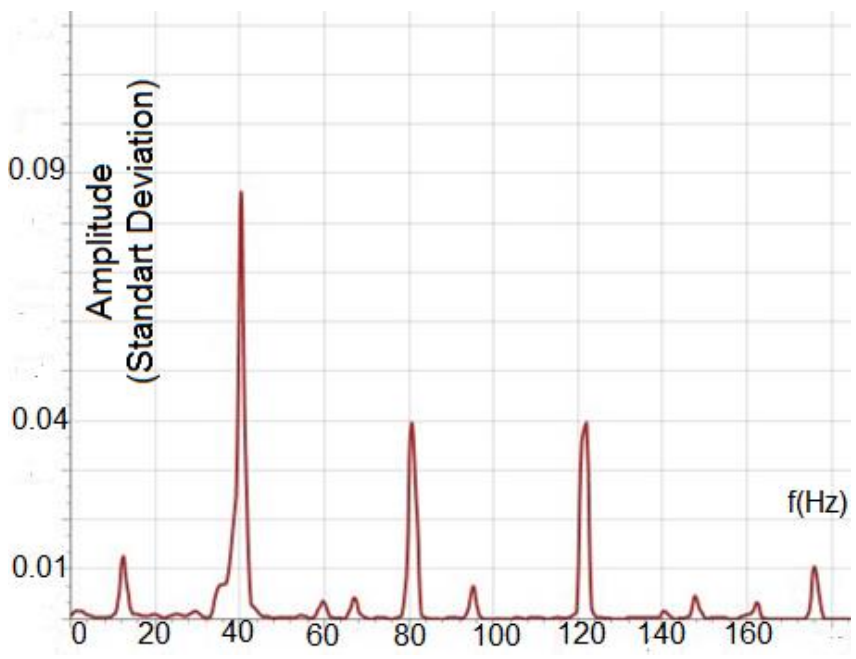

Figure 6. PSD values 
According to the data gathered and processed; PSD analysis gives more detailed results in comparison with trend analysis.

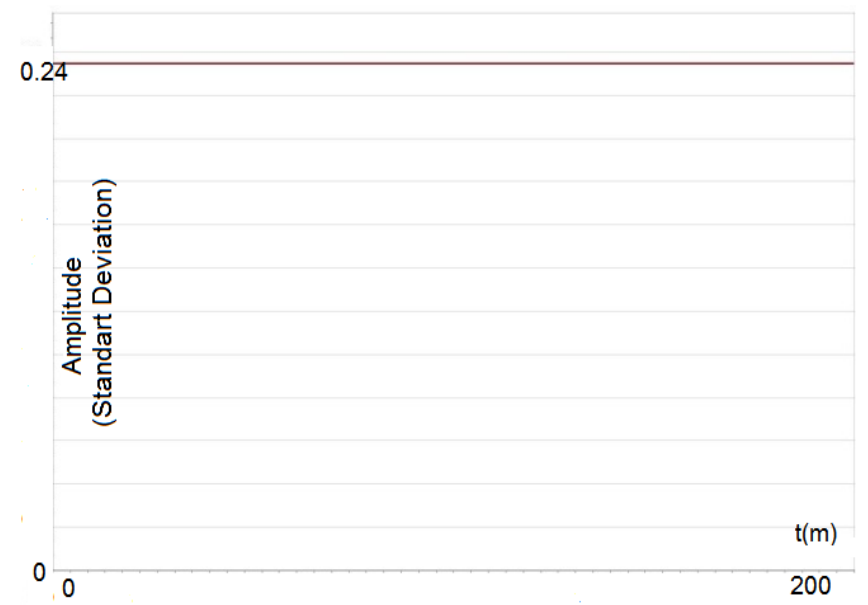

Figure 7. Trending values

According to evaluation of trend analysis in Figure 7; in comparison with the reference level, unbalance indicator has not detected any change in the condition of unbalance effect respect to the load on wings.

\section{Results and Conclusion}

In this test study, resonance effects of a test construction have been studied under the unbalance condition of a bearing in an electrical motor with the excitation of electricity frequency at $40.5 \mathrm{~Hz}$. Through predictive maintenance perspective; techniques of vibration and electrical consumption analysis are studied in order to identify the condition of a tested bearing under unbalance failure.

According to test results of vibration analysis; bearing failure frequencies and resonance frequencies are identified in spectrum domain under the effect of unbalance failure.

Electrical consumption analysis is successful on detection of unbalance failure in PSD analysis but not sensed in trend analysis. It is assumed that analysis programme of the measuring device is not designed for identifying resonance effect. But resonance effect may be studied in band of rotor or band of other; not exist sufficient data about it.

In comparison of vibration and electrical consumption analysis results; vibration analysis has been evaluated as more informative and superior tool for detecting the resonance features of the tested system in the condition of unbalance failure.area were described and presented.

\section{References}

[1] K.S. Jardine,, D. Lin, D. Banjevic, "A review on machinery diagnostics and prognostics", Mechanical Systems and Signal Processing, vol. 20, pp. 1483-1510, 2006.

[2] J. Lee, F. Wu, W. Zhao, M. Ghaffari, L. Liao, D. Siegel, "Prognostics and health management design for rotary machinery systems-Reviews,methodology and applications", Mechanical Systems and Signal Processing, vol. 42, pp. 314-334, 2014.

[3] J. Lee, E. Lapira,, B. Bagheri, H. Kao, "Recent advances and trends in predictive manufacturing systems in big data environment", Manufacturing Letters, vol. 1, pp. 38-41, 2013.

[4] W. Deleroi, "Squirrel cage motor with broken bar in the rotor - Physical phenomena an their experimental assessment", Proc. ICEM'82, Budapest, Hungary, 1982, pp. 767-770.

[5] J.A. Antonino-Daviu, , M. Riera-Guasp, , M. PinedaSánchez, J. Pons-Llinares, R. Puche-Panader, , "Feature extraction for the prognosis of electromechanical faults in electrical machines through the DWT", International Journal of Computational Intelligence Systems, vol. 2(2), 2012.

[6] T. Goodenow., W. Hardman, M. Karchnak., "Acoustic emissions in broadband vibration as an indicator of bearing stress", in: IEEE Aerospace Conference Proceedings, 2000, vol. 6, pp. 95-122.

[7] C. Costa, M. Kashiwagi, M. H. Mathias, "Rotor failure detection of induction motors by wavelet transform and Fourier transform in non-stationary condition", Case Studies in Mechanical Systems and Signal Processing, vol. 1, pp. 15-26, 2015. 